\title{
Design and Finite Element Analysis of Mechanical Spider
}

\author{
Urvil P Patel \\ Bachelor in Mechanical Engineering, Gujarat Technological University
}

\begin{abstract}
Mechanical spider is device which moves on eight legs. A leg is a combination of links. A linkage is developed that satisfy the design criteria and finite element analysis of mechanical spider is carried out in order to check the deformation of legs and stresses induced.
\end{abstract}

Keywords: Mechanical, Spider, Mechanism, Analysis

\section{Introduction}

It would be difficult to compete with the efficiency of a wheel on smooth hard surfaces but as condition increases rolling friction, this linkage becomes more viable and wheels of similar size cannot handle obstacles that this linkage is capable of. Toys could be developed that would fit in the palm of your hand and just large enough to carry a battery and a small motor. Eight leg mechanical spiders can be applicable for the making of robots. It has a wide range of application in the manufacturing of robots. A large version could use existing surveillance technology to convert your television into a real-time look at the world within transmitting range. In toy industries for making robotic toys it has got many applications. It can also be used for military purpose. By placing bomb detectors in the machines we can easily detect the bomb without harmful to humans. It can be used as heavy tanker machines for carrying bombs as well as carrying other military goods. It is also applicable in the goods industries for the small transportation of goods inside the industry. The mountain roads or other difficulties where ordinary vehicles cannot be moved easily can be replaced by our six leg mechanical spider. Heavy loads can be easily transported if we made this as a giant one. The geometry and conditions can be changed according to application needs. It can travel in rough surfaces very easily, so this machine can be used in rough surfaces were ordinary moving machine cannot travel.

\section{Construction}

A single leg is a six-bar linkage that consists of the frame, pinions, electric motor, crank, connecting arm, lower rocker, leg and an upper rocker. The ground points for the upper and lower rocker in this configuration are vertically in line to allow a coupled pair of legs to articulate like the front wheels of a typical car for steering.

The frame is made of aluminum because aluminum is light in weight and it is very important to reduce the weight of device as much as it is possible. Also other parts i.e. links are made of aluminum. Four gears and two pinions made of nylon material are used.

Electric motor is mounted on frame and pinion is connected at the shaft of electric motor. Two gears are in mesh with pinion on either side with the help of leg connection. The leg has a hip joint axially connected to the upper rocker arm in order to limit hip motion and a knee joint axially connected to connecting rod. The connecting rod has three axial connecting sites. The first connecting sites is for connecting knee, second is for crank connection and third is for connecting lower arm with connecting rod for limiting knee joint motion.

All links and final assembly is modeled in Creo parametric 2.0 as shown in figure.

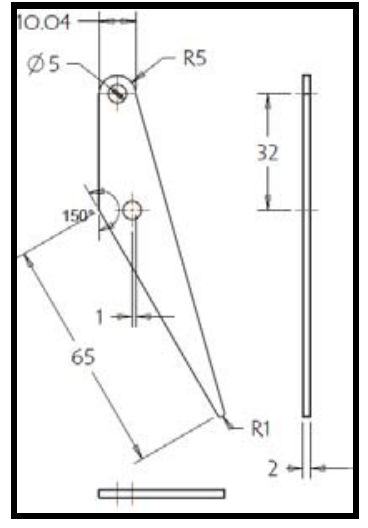

Link 1-Leg:

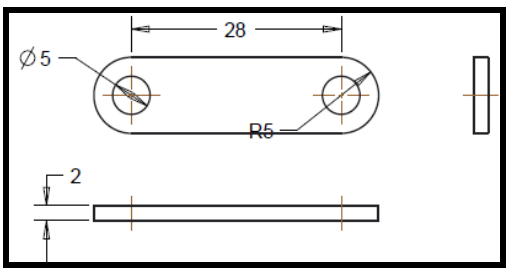

Link 2- Upper Rocker Arm

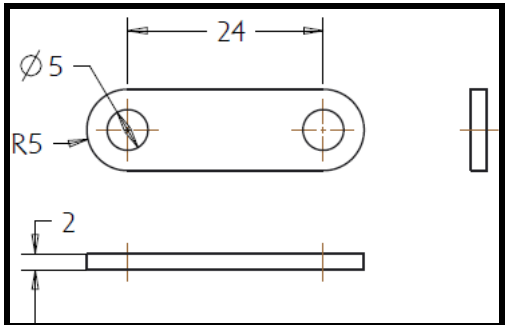

Link 3- Lower Rocker Arm 


\section{International Journal of Science and Research (IJSR)}

ISSN (Online): 2319-7064

Index Copernicus Value (2013): 6.14 $\mid$ Impact Factor (2014): 5.611

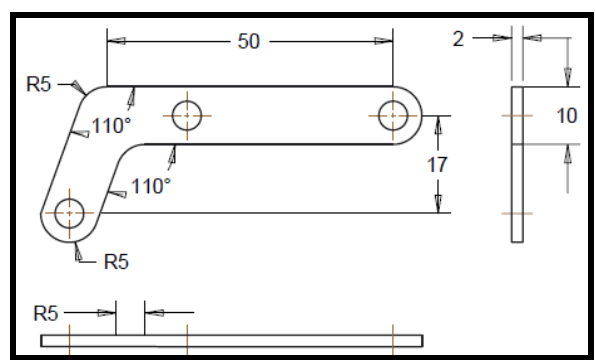

Link 4- Connecting Rod

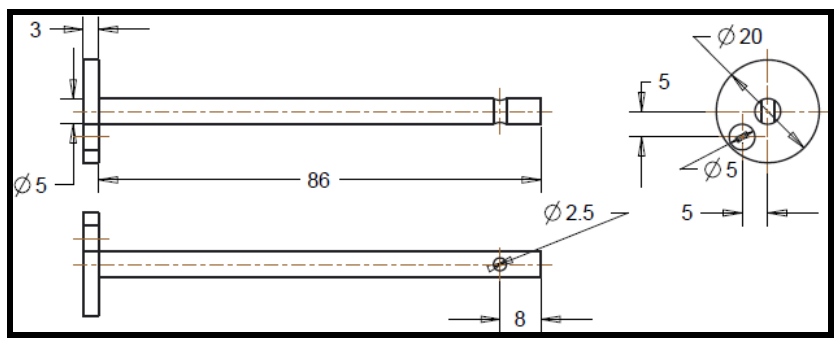

Link 5- Leg Connection

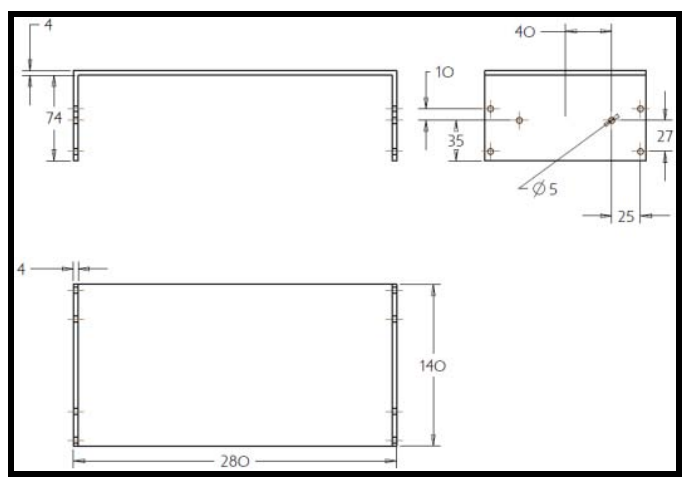

Frame 1

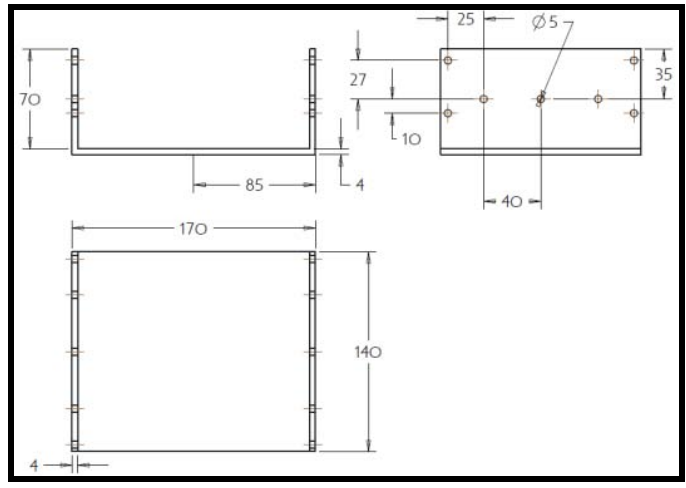

Frame 2 (Joint this with frame 1)

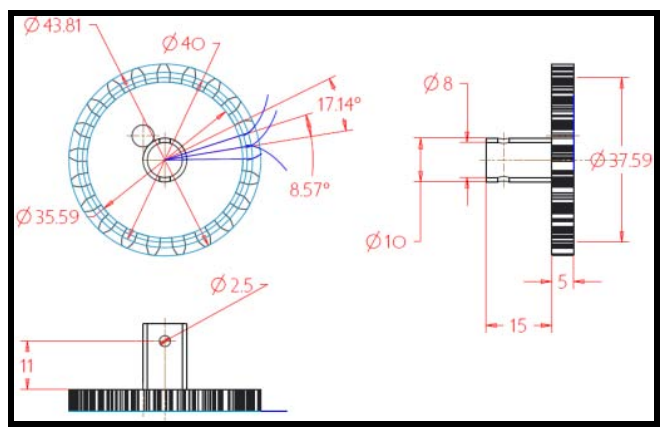

Gear and Pinion

\section{Mechanism}

Power is supplied by motor to pinion which in turn rotate crank i.e. gears and crank rotation is transferred to connecting arm causing leg to move in an accurate reciprocating movement. Instead of using motorized power, the device can also be manually powered. A single leg consists of five linkages and a crank made up of pivot joints that convert rotating motion into linear motion. The mechanism works on klann mechanism. For $180^{\circ}$ rotation of crank, straight-line portion of the path trace by the leg. For next $180^{\circ}$ of crank rotation, leg is raised to a predetermine height before returning to starting point and cycle is repeated. Figure shows the crank in $0^{\circ}, 90^{\circ}, 180^{\circ}$ and $270^{\circ}$ position along with path traced by links. Red curve trace out the path of each point for one complete revolution is shown.

Position 1: Path traced by each point at $0^{\circ}$

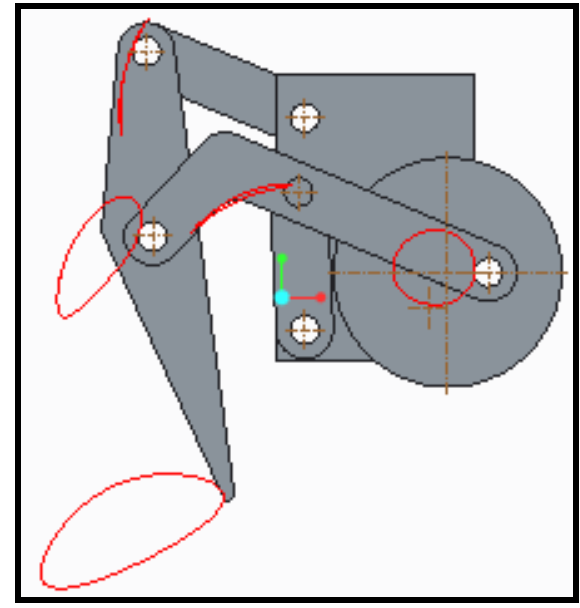

Position 2: Path traced by each point at $90^{\circ}$

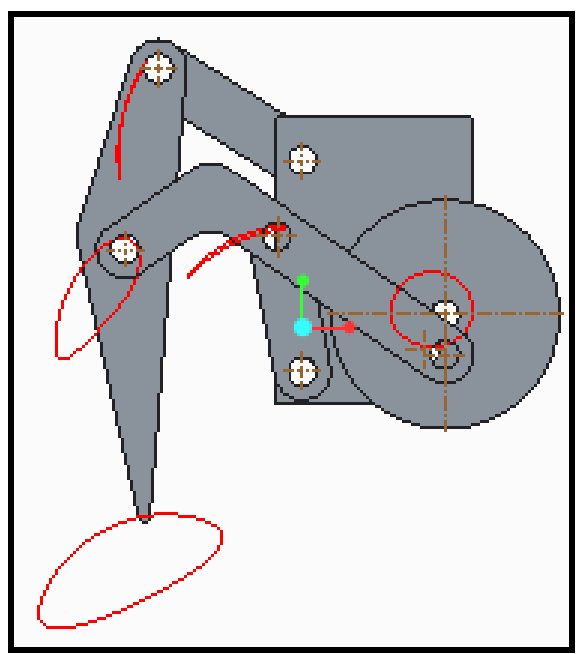

Position 3: Path traced by each point at $180^{\circ}$ 


\section{International Journal of Science and Research (IJSR) \\ ISSN (Online): 2319-7064}

Index Copernicus Value (2013): 6.14 | Impact Factor (2014): 5.611

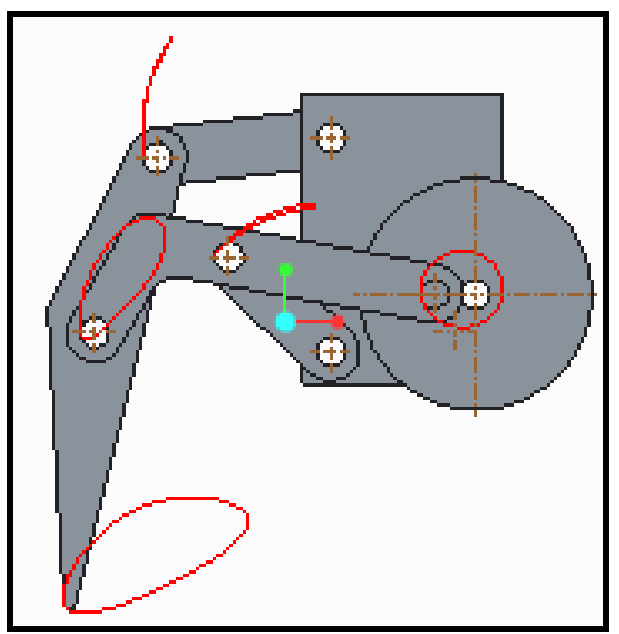

Position 4: Path traced by each point at $270^{\circ}$

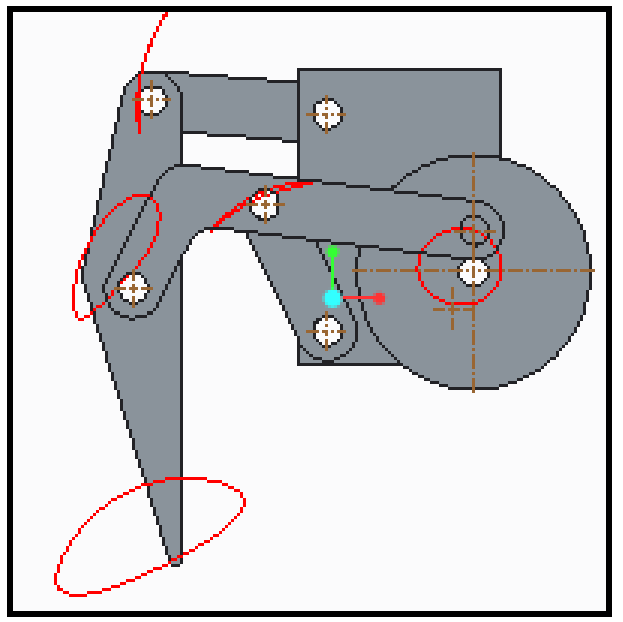

\section{Assembly of Mechanical Spider}

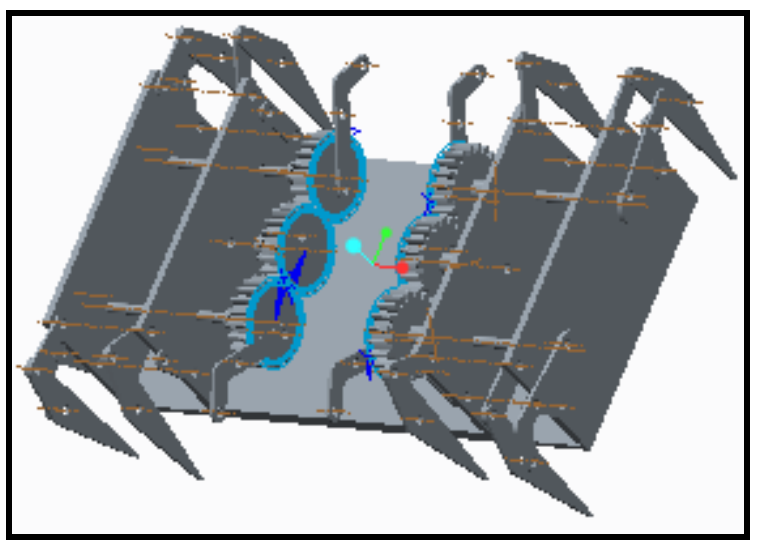

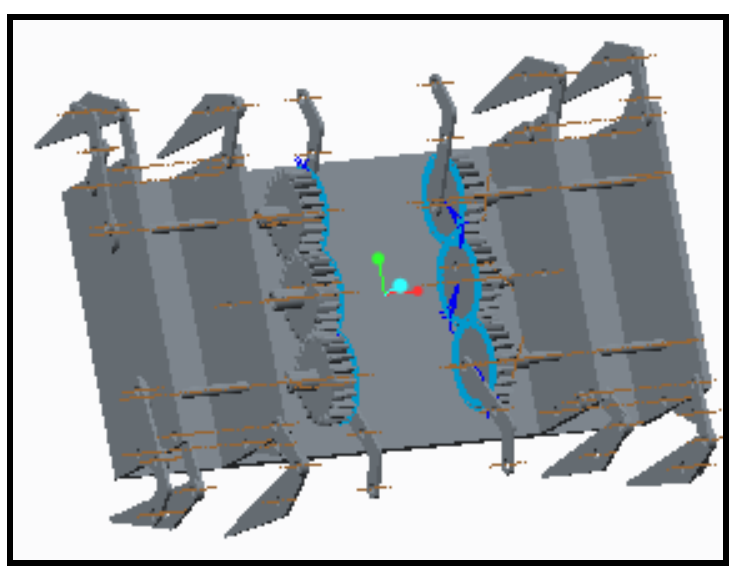

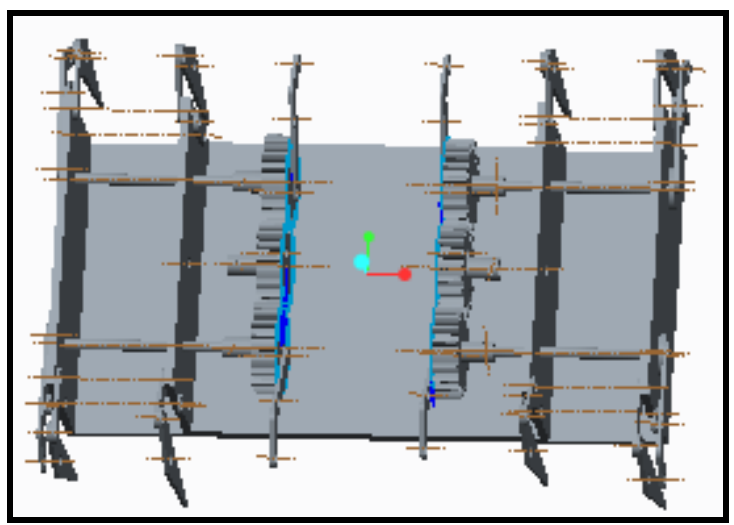

\section{Analysis of Mechanical Spider}

Before doing fabrication work of all parts and assembling, it is necessary to check out deformation and stress in the mechanical spider.

\subsection{Material Assign:}

Aluminum is assign to all linkages and fames and nylon material is assign to gears. Since mechanical spidervis symmetic on both side of the center plane, considering only half position since result will be same on both side. Also this will reduce the solving time.

\subsection{Contacts:}

When two separate surfaces touch each other such that they become mutually tangent, they are said to be in contact. Contact is changing-status nonlinearity. That is, the stiffness of the system depends on the contact status, whether parts are touching or separated.

Since all links are in motion, thus revolute joint is given between contacts of parts. Between gears bonded contact is given.

\subsection{Meshing:}

FEA uses a complex system of points called nodes which make a grid called a mesh. This mesh is programmed to contain the material and structural properties which define how the structure will react to certain loading conditions. Nodes are assigned at a certain density throughout the 


\section{International Journal of Science and Research (IJSR) \\ ISSN (Online): 2319-7064 \\ Index Copernicus Value (2013): 6.14 | Impact Factor (2014): 5.611}

material depending on the anticipated stress levels of a particular area. Regions which will receive large amounts of stress usually have a higher node density than those which experience little or no stress. Points of interest may consist of: fracture point of previously tested material, fillets, corners, complex detail, and high stress areas. The mesh acts like a spider web in that from each node, there extends a mesh element to each of the adjacent nodes. This web of vectors is what carries the material properties to the object, creating many elements.

Elements: When two nodes get combine the form an element. Nodes are similar to the points in geometry and represent the corner points of an element. The element shape can be changed by moving the nodes in space. Element is an entity into which the system under study is divided. An element shape is specified by nodes. The shape (area, length, and volume) of an element depends on the nodes with which it is made.

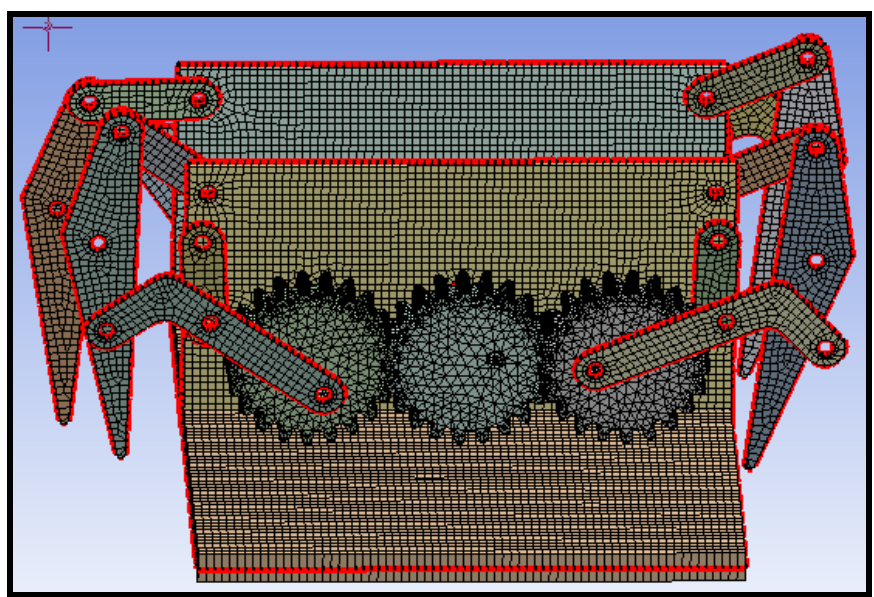

Meshing

Number of nodes: 92454

Number of elements: 55921

\subsection{Loading and Boundary Conditions:}

Boundary Conditions: the loads and constraints that represent the effect of the surrounding environment on the model. (Everything else that you have not modelled) Types of Boundary Conditions: constraints and loads. Mechanical spider is fixed at four edges.

Loads: forces, moments, pressures, temperatures, accelerations. Constraints: Resist the deformations induced by the loads.

Acceleration is given in $\mathrm{Z}$ direction.

Acceleration:

- Acts on entire model in length/time2 units.

- Acceleration can be defined by Components or Vector.

- Body will move in the opposite direction of the applied acceleration. Thus acceleration is given in upward direction.
- Acceleration is considered 5 times gravitational force i.e. $5 \mathrm{~g}=5 * 9810$.

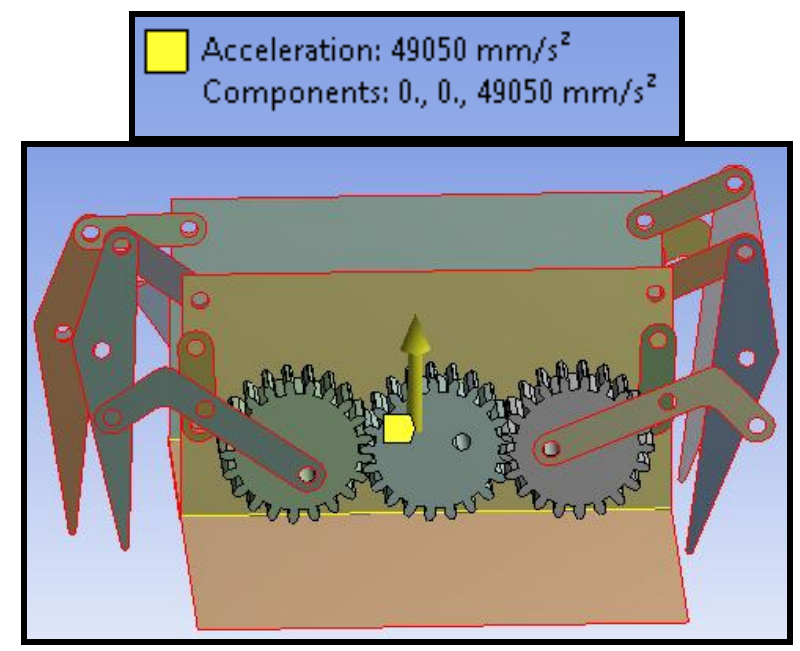

4.5 Result of Static Structural Anslysis:

Stress: It is define as force of resistance offered by a body against the deformation.

Von-mises stress was found to be within limit and thus there were no high stress in the body.

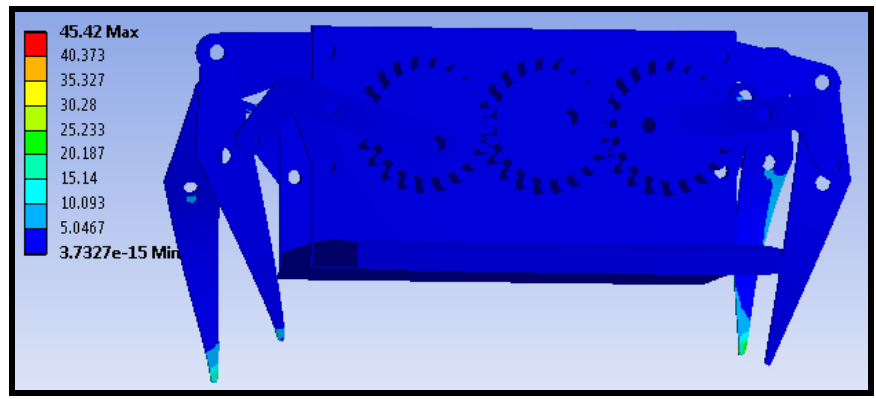

Total deformation of the body was within acceptable limit because deformation was marginal.

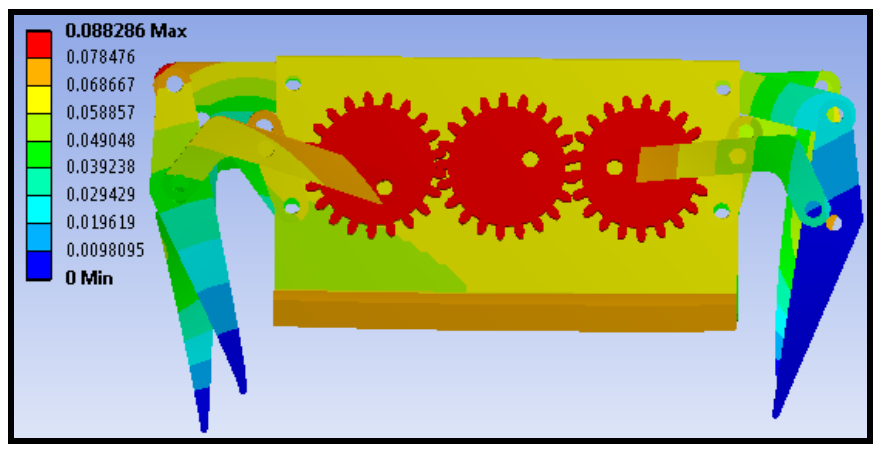




\section{International Journal of Science and Research (IJSR) \\ ISSN (Online): 2319-7064}

Index Copernicus Value (2013): 6.14 | Impact Factor (2014): 5.611

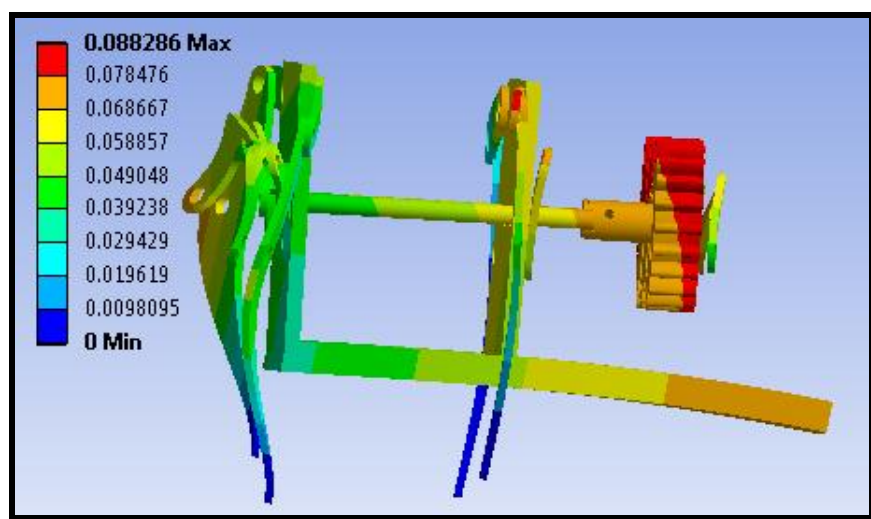

Total Deformation

\subsection{Result of Modal Analysis:}

Modal analysis determine the vibration characteristic i.e. natural frequencies and mode shapes of a structure or a machine component while it is being design. The natural frequencies and mode shapes are important parameters in the design of a structure for dynamic loading conditions.

The procedure for a modal analysis consists of four main steps:

1. Build the model.

2. Apply loads and obtain the solution.

3. Expand the modes.

4. Review the results.

\begin{tabular}{|l|l|l|}
\hline & Mode & \multicolumn{1}{|l}{ Frequency $[\mathrm{Hz}]$} \\
\hline 1 & 1. & 0. \\
\hline 2 & 2. & $1.3428 \mathrm{e}-003$ \\
\hline 3 & 3. & $4.891 \mathrm{e}-003$ \\
\hline 4 & 4. & 151.7 \\
\hline 5 & 5. & 165.48 \\
\hline 6 & 6. & 171.28 \\
\hline 7 & 7. & 176.75 \\
\hline 8 & 8. & 258.81 \\
\hline 9 & 9. & 335.33 \\
\hline 10 & 10. & 391.37 \\
\hline 11 & 11. & 398.98 \\
\hline 12 & 12. & 400.21 \\
\hline 13 & 13. & 574.47 \\
\hline 14 & 14. & 643.37 \\
\hline 15 & 15. & 689.35 \\
\hline 16 & 16. & 719.12 \\
\hline 17 & 17. & 932.69 \\
\hline 18 & 18. & 1019. \\
\hline 19 & 19. & 1063.6 \\
\hline 20 & 20. & 1137.1 \\
\hline \hline
\end{tabular}

Modes are expanded and deformational on each mode is determined.

Deformation at least and highest frequency is within limit and thus body is found to be safe.

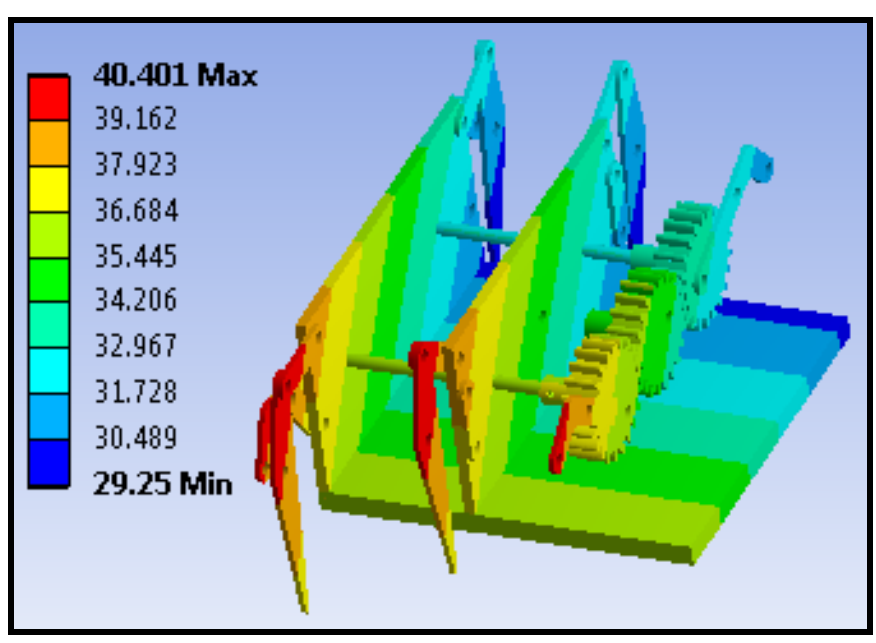

Thus using software Ansys workbench, finite element analysis of mechanical spider of any size can be done in order to check the deformation and stresses in the body.

\section{Advantages}

- Highly efficient as replacement of wheels.

- Constructing cost is low.

- Require less maintenance.

- Capable of carrying heavy loads.

- Easy to operate.

\section{Disadvantages}

- Lots of power is required to run.

- Speed is limited.

- Running is not smooth.

\section{Application}

1. Useful on uneven surfaces.

2. Useful in army for bomb detection and carry weapons.

3 . Useful in industries in place of different conveyors.

4. Useful in carrying heavy weights.

5. Useful in carrying objects through the river where using boats becomes costly.

\section{References}

[1] http://www.mechanicalspider.com/index.html.

[2] http://www.mekanizmalar.com/mechanicalspider.html.

[3] http://www.xtremeprojects.net/2012/01/mechanicalengineering-project-mechanical-spider.html

Deformation at one of the frequency: 